\title{
Exposure to second hand smoke: a survey of pregnant women visiting tertiary care hospitals of Peshawar
}

\author{
Momal Fatima, Khadija Nowaira Abdullah, Momina Rahman, Parivash Bangash, Mashal Rasheed, \\ Nayab Shabir, Neelofar Nishad
}

Submitted

July 17, 2021

Accepted

August 07, 2021

Author Information

Dr. Momal Fatima

House Officer

Nishtar Hospital, Multan,

Punjab, Pakistan

Dr. Khadija Nowaira

Abdullah

Assistant Professor

Department of Community

Medicine, Rehman Medical

College, Peshawar, Khyber

Pakhtunkhwa, Pakistan

(Corresponding Author)

Email:

khadija.nowaira@rmi.edu.pk

From: Kuwait Teaching

Hospital, Peshawar, Khyber

Pakhtunkhwa, Pakistan

Dr. Momina Rahman

House Officer

Dr. Parivash Bangash

House Officer

Dr. Mashal Rasheed

House Officer

Dr. Nayab Shabir

House Officer

Dr. Neelofer Nishat

House Officer

Citation: Fatima M, Abdullah KN, Rahman M, Bangash P, Rasheed M, Shabir N, et al. Exposure to second hand smoke: a survey of pregnant women visiting tertiary care hospitals of Peshawar. J Rehman Med Inst. 2021 JulSep;7(3):12-5.

\begin{abstract}
Introduction: Second hand smoke (SHS) is reported to cause 890,000 deaths annually worldwide. It is also a known cause of serious complications in pregnancy. The current study intends to fill in some of the knowledge gap for further research \& effective public health interventions.
\end{abstract}

Objective: To estimate the magnitude of exposure to second hand smoke and assess awareness about it among pregnant women visiting four selected tertiary care hospitals of Peshawar.

Materials \& Methods: A descriptive cross-sectional study was conducted at four tertiary hospitals of Peshawar from $1^{\text {st }}$ January to $1^{\text {st }}$ March 2018. Non-probability serial sample of 410 pregnant women was taken. A structured questionnaire was used to collect data. Data were analysed for descriptive statistics using SPSS version 22.

Results: A total of 410 pregnant women were included. The mean age was $21 \pm 4$ years; $149(36.3 \%)$ of the total subjects were exposed to SHS, highest frequency (49\%) being in age group 26-35 years. Exposure to SHS was highest (39\%) among illiterate ladies; $92 \%$ of the subjects were exposed to SHS at home, the main source being their husbands (46\%); $40.7 \%$ of the subjects were aware of the adverse effects of SHS on fetus, younger $(p=0.01) \&$ more educated women $(p=0.001)$ being more likely to be aware.

Conclusions: Exposure of pregnant women to second hand smoke is a public health concern in Peshawar, being more likely among younger, less educated, unaware women, and housewives.

Keywords: Second Hand Smoke; Passive Smoking; Tobacco Smoke Pollution; Pregnant Women; Awareness.

The authors declared no conflict of interest. All authors contributed substantially to the planning of research, data collection, data analysis, and write-up of the article, and agreed to be accountable for all aspects of the work.

\section{INTRODUCTION}

During smoking, all of the smoke is not inhaled. In fact, most of it goes into the air for any nearby person to breathe it in involuntarily. This is called Second Hand Smoke (SHS) which is a mixture of smoke from not only the burning end of a cigarette but also the smoke breathed out by smokers ${ }^{1}$. It is known to contain more than 7,000 chemicals; $;{ }^{1,2}$ out of these together, hundreds are teratogens and carcinogens. ${ }^{2,3}$ Second hand smoking is breathing someone else's cigarette smoke for at least 15 minutes per day and for at least 3 days a week. ${ }^{4}$ It is reported that $40 \%$ of children, $33 \%$ of male nonsmokers and $35 \%$ of female non-smokers are exposed to SHS worldwide. ${ }^{5}$ An estimated more than 600,000 death per year occur due to secondhand smoke (SHS) which is more than $1 \%$ of all global deaths; 165,000 of the victims are children. ${ }^{6}$ Out of the total deaths that are attributed to SHS, $47 \%$ occur in women, $28 \%$ in children, and $26 \%$ in men. ${ }^{6}$ According to a survey, 2.5 million Americans have lost their life to SHS since $1964 .^{3}$

The largest number of estimated deaths attributable to SHS exposure are caused by ischemic heart disease in adults, followed by lower respiratory tract infections in children, and asthma in adults. In assessment of burden of disease in terms of disability-adjusted life years (DALYs) lost due to exposure to SHS, lower respiratory tract infections among children are responsible for most of the lost DALYs. ${ }^{6}$ It is also established that those exposed to SHS are at $30 \%$ higher risk of getting lung cancer and many other types of cancer. ${ }^{6}$ Almost half of the total burden attributable to exposure to SHS is borne by southeast Asia and the western Pacific. However, a high burden of disease is also estimated in Eastern Europe, Africa, and Eastern Mediterranean region.

Women and children suffer disproportionately negative health outcomes of SHS. Women are 50\% less likely to be smokers, but suffer more due to SHS. Pregnant women are exposed to many risk factors affecting maternal and infant mortality \& morbidity. ${ }^{7}$ SHS is one of the preventable cause of adverse outcomes of pregnancy 8,9 It is welldocumented that maternal smoking during pregnancy, first hand or second hand, is associated with detrimental effects such as stillbirth, preterm 
birth, small for gestation babies, and Sudden Infant Death Syndrome (SIDS). ${ }^{10-12}$

Meconium analysis indicates that nicotine metabolite concentration in infants of SHS is same as in infants of active light smokers. ${ }^{5}$ In developing countries little attention has been given to such an important public health issue \& the available data are largely deficient. SHS has been a neglected research area in general in the case of Pakistan \& most of the useful evidence comes from Global Adult Tobacco Survey (2014) conducted by WHO ${ }^{13}$ The survey found that about 7 in 10 adults (16.8 million adults) are exposed to tobacco smoke at the workplace while 5 in 10 (56.3 million adults) are exposed at home. Despite the known preventable complications of SHS exposure during pregnancy in terms of maternal \& fetal mortality \& morbidity, it has not received much needed focus. Data in general, and addressing SHS and women's health in particular, are very scarce.

The current study was done to find the magnitude of exposure to SHS among pregnant women in Peshawar, Pakistan, assess awareness about it, \& explore some of the social factors associated with lack of awareness. The study findings can also inform public health professionals in designing effective interventions for the control of second-hand smoke among this important population segment.

\section{MATERIALS \& METHODS}

The cross-sectional descriptive survey was conducted from $1^{\text {st }}$ January to $1^{\text {st }}$ March 2018. Non-probability serial sampling was applied. The minimum sample calculated by WHO sample predictor was 400 . A total of 410 pregnant women visiting the Gynecology Outpatient departments of two private and two public sector tertiary hospitals of Peshawar were included in the study. Subjects who were in distress \& needed early medical care were excluded.

A structured questionnaire was used to collect data. The questionnaire included three sections. The first section consisted of demographic data, the second section included questions about exposure to SHS, while the third section explored awareness among participants. A pilot study was carried out at one of the private sector hospitals to refine the tool. The questionnaire was translated in local languages of Urdu and Pashto to facilitate the participants.

Ethical approval was taken from Institutional Review Committee. An informed verbal consent was taken from subjects. Formal permission was taken from the Medical Directors of the concerned hospitals and Heads of Gynecology Department of all four tertiary teaching hospitals.

Data were entered and analyzed in SPSS Version 21. The frequencies were estimated and $95 \%$ confidence intervals were calculated. The Chi Square test was used for comparison of categorical variables considering $p \leq 0.05$ as significant.

\section{RESULTS}

Out of 410 subjects included in the study, mean age was $21 \pm 4$ years. Majority of the subjects fell into 15-25 years age group. The details of sample characteristics are given in Table 1.

Out of total 410 women, 149 (36.3\%) were exposed to SHS. Majority of the second-hand smokers were housewives (84\%) and illiterate (39\%). About half of the women exposed to SHS were aged 26-35 years (49\%). More details relevant to exposure are also shown in Table 1.

Table 1: Sample characteristics \& exposure to SHS $(n=410)$.

\begin{tabular}{|l|l|c|c|c|}
\hline \multicolumn{2}{|c|}{ Characteristics } & Frequency (\%) & SHS Exposure f (\%) & $\begin{array}{c}\text { Percentage of exposed } \\
(\mathbf{n = 1 4 9 )}\end{array}$ \\
\hline \multirow{4}{*}{ Age group (years) } & $15-25$ & $216(52.7)$ & $66(30.5)$ & 44.3 \\
\cline { 2 - 5 } & $26-35$ & $167(40.7)$ & $73(43.7)$ & 49.0 \\
\cline { 2 - 5 } & 36 \& above & $27(6.6)$ & $10(37.0)$ & 06.7 \\
\hline \multirow{4}{*}{$\begin{array}{l}\text { Educational } \\
\text { status }\end{array}$} & Illiterate & $166(40.5)$ & $58(35.0)$ & 39.0 \\
\cline { 2 - 5 } & Primary & $75(18.3)$ & $27(36.0)$ & 18.1 \\
\cline { 2 - 5 } & Secondary & $59(14.4)$ & $24(40.7)$ & 16.1 \\
\cline { 2 - 5 } & Higher & $35(8.5)$ & $16(45.7)$ & 10.7 \\
\cline { 2 - 5 } & Informal & $75(18.3)$ & $24(32.0)$ & 83.9 \\
\hline \multirow{2}{*}{$\begin{array}{c}\text { Employment } \\
\text { status }\end{array}$} & Housewives & $370(90.2)$ & $125(33.8)$ & 16.1 \\
\cline { 2 - 5 } & Working women & $40(9.8)$ & $24(60.0)$ & \\
\hline
\end{tabular}

As given in table 2, most of the subjects were exposed to second hand smoke at home (92\%); the most frequent sources of exposure were husbands (46\%), followed by sons (20.3\%), and father / father-in-law (20\%).

Table 2: Place \& source of SHS exposure $(n=149)$.

\begin{tabular}{|l|l|c|}
\hline \multicolumn{2}{|c|}{ Characteristics } & Frequency of exposure (\%) \\
\hline \multirow{4}{*}{ Place of exposure } & Home & $137(92.0)$ \\
\cline { 2 - 3 } & Workplace & $09(06.0)$ \\
\cline { 2 - 3 } & Both & $03(02.0)$ \\
\hline \multirow{4}{*}{ Source of SHS } & Husband & $68(46.0)$ \\
\cline { 2 - 3 } & Father/father-in-law & $30(20.0)$ \\
\cline { 2 - 3 } & Son & $31(20.3)$ \\
\cline { 2 - 3 } & Brother/brother-in-law & $11(07.7)$ \\
\cline { 2 - 3 } & Others/colleagues & $09(06.0)$ \\
\hline
\end{tabular}


Among 410 pregnant women, 168(41\%) were aware that there are adverse effects of SHS on fetus while 242(59\%) either thought that SHS has no harmful effects or had no idea about it. Majority $(55 \%)$ of the pregnant women who were aware about the hazardous effects of SHS reported the electronic and print media to be the source of their knowledge, this was followed by other sources 49(29\%). Lastly doctors were the source of information for only $27(16 \%)$ of them.

As shown in figure 1, when frequency of awareness about hazardous effects of SHS on smoking was compared by age, the women in the youngest age group (15-25yrs) were most aware while those 36 years or above of age were least aware. The difference of frequencies was statistically significant $(p 0.01)$.

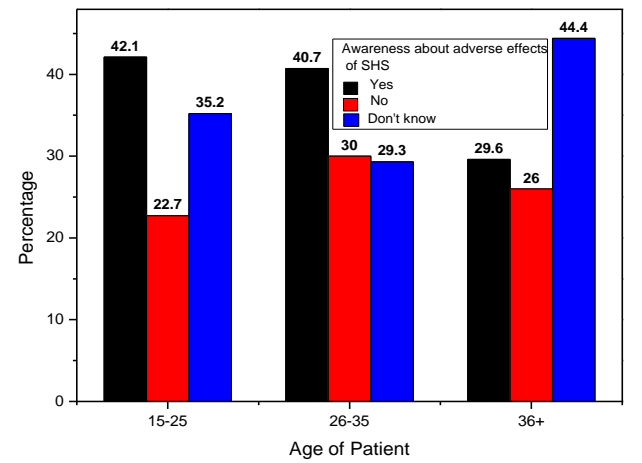

Figure 1: Frequency of awareness by age group

Frequency of awareness increased with higher education level as evident in figure 2 . The difference of frequency by educational level was also statistically significant ( $p 0.001)$.

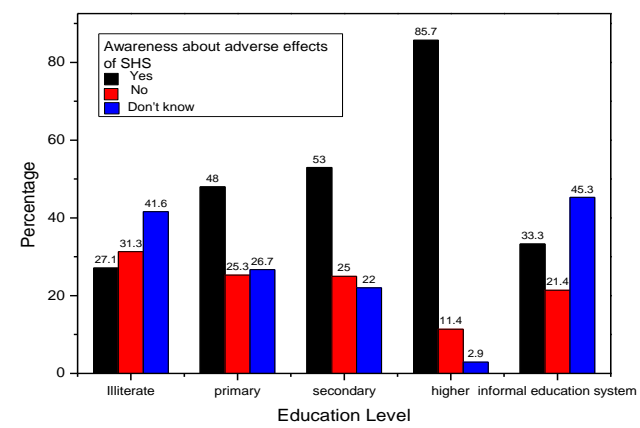

Figure 2: Awareness by educational level

Working women were slightly more aware (43\%) about hazards of SHS than the housewives $(41 \%)$ but the difference was statistically not significant $(p=0.20)$.

\section{DISCUSSION}

The study is the first survey of its kind to be conducted in Peshawar and focuses on an important but neglected public health issue. It provides baseline data for further research studies and much needed public health interventions.

More than $36 \%$ of the pregnant women, a considerable proportion, were found to be secondhand smokers. This is not surprising though as pregnant women in specific are considered a "vulnerable population". ${ }^{14-15}$ Furthermore, it may be due to the expected gender inequalities regarding decision making in developing countries like Pakistan. ${ }^{16}$ It is important to note that direct comparison of most of the conducted studies on SHS is not justifiable as each one has applied different operational definition of SHS and is conducted in different setting. Still, the reported prevalence of SHS in non-smoking pregnant women in other developing countries in general is similar to the finding of the present study ${ }^{17}$ Not surprisingly, this study found that husbands were the source of SHS for most of the pregnant women. The social norms do not allow for not permitting the husband to smoke or avoiding the exposure even if the expecting mother is aware of the hazardous effects on herself \& the fetus. This is consistent with the results of studies conducted in countries with somewhat similar social norms, such as India, Malaysia and China. ${ }^{18-20}$

The current study revealed that exposure to SHS is more frequent among pregnant women younger than 36 years, housewives and among less educated women. This could be explained, as young Pakistani women may not be empowered enough to take control of their own health due to social norms. Housewives are mostly at home and joint family system still prevails, therefore they are likely to be exposed to SHS at home. Education is related to awareness \& empowerment which in turn may help the pregnant women make healthy choices. Studies from other developing countries $^{18-19}$ and many developed countries ${ }^{21-22}$ have also identified younger age, being a housewife, and lesser education as potential risk factors for exposure to SHS among pregnant women.

Our study showed that $41 \%$ of the pregnant women were aware that SHS has deleterious effects on the fetus. The fact that most of the subjects were illiterate well explains the finding. The finding is supported by studies conducted in $\operatorname{India}^{18}$ \& Saudi Arabia ${ }^{23}$ which showed limited awareness about effects of SHS on fetus among the participating pregnant women. Younger women were more aware about the hazards of SHS; this could be because of increasing social media use as a source of information.

The main sources of awareness identified were print $\&$ electronic media. The potential role of media for controlling smoking has already been identified, ${ }^{24}$ the current study reconfirms that. The finding that doctors are the least common source of information about the hazardous effects of SHS raises concern \& hints at the gap in health education services at healthcare settings in general.

\section{LIMITATIONS}

As the survey was conducted in tertiary care hospitals, it has limited generalizability. Also, as the exposure to SHS was selfreported by the subjects, recall bias is a potential limitation of the study.

\section{CONCLUSION}

The study confirmed that SHS among younger, less educated and unemployed pregnant women is a major public health issue of concern in Peshawar. The most frequent source of SHS are husbands. Majority of the women are unaware of the potential harmful effects of SHS on fetus. 


\section{RECOMMENDATIONS}

It is recommended to conduct population-based larger and more generalizable studies. Public health awareness campaigns should be launched via media. Health education and counselling of couples \& families by healthcare professionals at all healthcare levels and settings should also be ensured to address this growing concern. Health and education sector need to effectively collaborate to bring a conducive social change for a long term solution of this public health menace.

\section{REFERENCES}

1. U.S. Department of Health and Human Services. A Report of the Surgeon General: How Tobacco Smoke Causes Disease: What It Means to You. Atlanta: U.S. Centers for Disease Control and Prevention, Office on Smoking and Health, 2010 [online] Available <https://www.cdc.gov/tobacco/data_statisti cs/sgr/2010/consumer_booklet/index.htm> [Accessed 15 April, 2021].

2. Centers For Disease Control \& Prevention. Health Effects of Secondhand Smoke, 2020 [Online]

Available<https://www.cdc.gov/tobacco/da ta_statistics/fact sheets/secondhand index.htm> [Accessed 15 April, 2021].

3. U.S. Department of Health and Human Services. The Health Consequences of Smoking - 50 Years of Progress: A Report of the Surgeon General. Atlanta: U.S. Office on Smoking and Health, 2014 [Online] Available https://www.cdc.gov/tobacco/data_statistic s/sgr/50th-anniversary/index.htm [Accessed 15 April, 2021].

4. Leonardi-Bee J, Britton J, Venn A. Second hand Smoke and adverse foetal outcomes in non-smoking pregnant women: a metaanalysis. Pediatrics. 2011; 127 (4), 734-41.

5. Lee J, Lee DR, Lee DH, Paek YJ, Lee WC. Influence of maternal environmental tobacco smoke exposure assessed by hair nicotine levels on birth weight. Asian Pac J Cancer Prev. 2015; 16(7):3029-34. doi: 10.7314/apjcp.2015.16.7.3029. PMID: 25854401.

6. Oberg M, Jaakkola MS, Woodward A, Peruga A, Prüss-Ustün A. Worldwide burden of disease from exposure to secondhand smoke: a retrospective analysis of data from 192 countries. Lancet. 2011 Jan 8;377(9760):139-46. doi: 10.1016/S01406736(10)61388-8. PMID: 21112082.

7. World Health Organization. Quantifying environmental health impacts.2011. [Online] Available <https://www.who.int/quantifying_ehimpa cts/publications/shsarticle2010/en/\#: :text $=$ More $\% 20$ than $\% 20600 \% 20000 \% 20$ death, also $\% 201.8 \% 20$ billion $\% 20$ non $\%$ 2Dsmokers> [Accessed 16 April, 2021].

8. Hackshaw A, Rodeck C, Boniface S. Maternal smoking in pregnancy and birth defects: a systematic review based on 173 687 malformed cases and 11.7 million controls. Hum Reprod Update. 2011 SepOct;17(5):589-604. doi: 10.1093/humupd/dmr022. Epub $2011 \mathrm{Jul}$ 11. PMID: 21747128; PMCID: PMC3156888.

9. Salmasi G, Grady R, Jones J, McDonald SD. Environmental tobacco smoke exposure and perinatal outcomes: a systematic review and meta-analyses. Acta Obstet Gynecol Scand. 2010;89(4):423-41. doi: 10.3109/00016340903505748. PMID: 20085532

10. Hawsawi AM, Bryant LO, Goodfellow LT. Association between exposure to secondhand smoke during pregnancy and low birthweight: a narrative review. Respir Care. 2015 Jan;60(1):135-40. doi: 10.4187/respcare.02798. Epub 2014 Jul 8. PMID: 25006271.

11. Ko TJ, Tsai LY, Chu LC, Yeh SJ, Leung C, Chen CY, et al. Parental smoking during pregnancy and its association with low birth weight, small for gestational age, and preterm birth offspring: a birth cohort study. Pediatr Neonatol. 2014 Feb;55(1):20-7. doi: 10.1016/j.pedneo.2013.05.005. Epub 2013 Jul 12. PMID: 23850094.

12. Marufu TC, Ahankari A, Coleman T, Lewis S. Maternal smoking and the risk of still birth: Systematic review and metaanalysis. BMC Public Health. 2015;15:239. doi: 10.1186/s12889-015-1552-5.

13. World health organization. Pakistan Global Adult Tobacco Survey data.2014. [Online] Available

<https://www.who.int/tobacco/surveillance /survey/gats/pak/en/ > [Accessed 17 April, 2021].

14. World Medical Association. "Declaration of Helsinki. Ethical Principles for Medical Research Involving Human Subjects" Jahrbuch für Wissenschaft und Ethik. 2019;14(1):233-8. https://doi.org/10.1515/9783110208856.23 3.

15. Shivayogi P. Vulnerable population and methods for their safeguard. Perspect Clin Res. 2013;4(1):53-57. doi:10.4103/22293485.106389.

16. Kennedy E, Binder G, Humphries-Waa K, Tidhar T, Cini K, Comrie-Thomson L, et al. Gender inequalities in health and wellbeing across the first two decades of life: an analysis of 40 low-income and middleincome countries in the Asia-Pacific region. The Lancet. Global health 8 (12): e1473e1488. 10.1016/s2214-109x(20)30354-5.

17. Reece S, Morgan C, Parascandola M, Siddiqi K. Secondhand smoke exposure during pregnancy: a cross-sectional analysis of data from Demographic and Health Survey from 30 low-income and middleincome countries. Tob Control. 2019 Jul;28(4):420-426. doi: 10.1136/tobaccocontrol-2018-054288. Epub 2018 Jul 19. PMID: 30026189.

18. Mistry R., Dasika A. Antenatal Tobacco Use and Secondhand Smoke Exposure in the Home in India. Nicotine Tob Res. 2018 Jan 5;20(2):258-261. doi: 10.1093/ntr/ntx049. PMID: 28339916.

19. Norsa'adah B, Salinah O. The Effect of Second-Hand Smoke Exposure during Pregnancy on the Newborn Weight in Malaysia. Malays J Med Sci. 2014;21(2):44-53.

20. Lang L, Tong EK, Mao Z, Hu TW. Exposure to secondhand smoke and associated factors among non-smoking pregnant women with smoking husbands in Sichuan province, China. Acta Obstet Gynecol Scand. 2010;89(4):549-57. doi: 10.3109/00016341003713851. PMID: 20367430; PMCID: PMC3759004.

21. Drake P, Driscoll AK, Mathews TJ. Cigarette Smoking During Pregnancy: United States, 2016. NCHS Data Brief. 2018 Feb;(305):1-8. PMID: 29528282.

22. Do EK, Green TL, Prom-Wormley EC, Fuemmeler BF. Social determinants of smoke exposure during pregnancy: Findings from waves $1 \& 2$ of the Population Assessment of Tobacco and Health (PATH) Study. Prev Med Rep. 2018;12:312-320. doi:10.1016/j.pmedr.2018.10.020.

23. Al-Shaikh GK, Alzeidan RA, Mandil AM, Fayed AA., Marwa B, Wahabi HA. Awareness of an obstetric population about environmental tobacco smoking. J Family Community Med. 2014;21(1):17-22. doi:10.4103/2230-8229.128768.

24. Lloyd A, Mckendrick J, Rutter A. The role of digital and social media within mass media anti-smoking campaigns. Tobacco Induced Diseases. 2018;16(1):217. doi:10.18332/tid/84020. 